\title{
Connecting with Strangers in the City: A Mattering Approach
}

\author{
Victoria Zeeb*1 and Helene Joffe ${ }^{1}$ \\ ${ }^{1}$ Division of Psychology and Language Sciences, UCL, United Kingdom \\ ${ }^{*}$ Corresponding author information: Victoria Zeeb, Division of Psychology and \\ Language Sciences, UCL, 26 Bedford Way, WC1H OAP, London, United Kingdom \\ (e-mail: victoria.zeeb@gmail.com).
}

In press in British Journal of Social Psychology

\begin{abstract}
:
A longstanding sociological tradition conceives of city life as profoundly alienating and insular (Durkheim, 1951; Simmel, 1903). As UK cities continue to grow, this could be detrimental as connecting with others is crucial for wellbeing (Kushlev, Heintzelman, Oishi \& Diener, 2018). Although the link between social connectedness with close others and wellbeing is well established, less is known about how connecting with strangers links to wellbeing, how strangers are represented by lay people and what motivates people's desire to connect. Drawing on Mattering theory and a Social Representations Approach, this study aims to examine common-sense thinking about and motivation for social connectedness with strangers in the contemporary British city. To do this, an interview study of 52 city dwellers in Britain's two largest cities, London and Birmingham, was conducted. The Grid Elaboration Method (Joffe and Elsey, 2014), a novel free association and interview technique, was applied. Thematic analysis revealed that representations of strangers exist on a continuum between 'good' and 'bad', are shaped by the contextual factors of place, time and technology, are built upon the 'self/other' thema and are motivated by a desire to 'matter'. This work has implications for creating wellbeing enhancing cities.
\end{abstract}

\section{Keywords:}

Mattering; Strangers; Wellbeing; Cities; Social Representations Approach

\section{Data availability statement:}

The data that support the findings of this study are available from the corresponding author upon reasonable request. 


\section{Connecting with Strangers in the City: A Mattering Approach}

Wellbeing is centrally influenced by people's relationships with other people (Diener, 2012, 2013; Diener, Suh, Lucas, \& Smith, 1999; Huppert, 2009; Jenkins et al., 2008; Morrow, 2001). Wellbeing, a multifaceted construct, encompasses individuals' feelings of satisfaction with life, whether they experience the things they do as worthwhile and positive emotions like happiness and a lack of anxiety (ONS, 2015). The evidence that social relationships are associated with wellbeing is so strong that it is now considered a 'fact' (Kushlev, Heintzelman, Oishi, \& Diener, 2018). The bulk of the existing evidence derives from research examining social relationships with 'strong ties' (Granovetter, 1973): family, romantic partners and, to some extent, friends (Diener \& Seligman, 2002; Dolan, Peasgood, \& White, 2008; Li \& Kanazawa, 2016; Pinquart \& Sörensen, 2000; Ueno, 2005). The emphasis in the literature has been on the social support given by 'strong tie' relationships. Yet interactions with weak ties - strangers and acquaintances - have also been shown to have wellbeing inducing benefits (Dunn, Biesanz, Human, \& Finn, 2007; M. W. Erber \& Erber, 2001; R. Erber, Wegner, \& Therriault, 1996). The impact of interacting with strangers is particularly pertinent to city life since higher population densities mean that strangers are regularly encountered. This paper explores whether, how and why interactions with strangers are associated with wellbeing by entering the perspectives of the dwellers in Britain's largest cities.

A key 'weak tie' relationship, connecting with a stranger, involves infrequent contact, low emotional intensity and limited intimacy (Sandstrom \& Dunn, 2014). The idea that 'weak tie' encounters can be wellbeing-giving is in line with formative social theory that argues that casual contact between city-dwellers can produce a vivacious atmosphere, a sense of joy and 'collective effervescence' (Jacobs, 1961; Jovchelovitch \& Priego-Hernandez, 2013; Simmel \& Hughes, 1949). Such encounters take place on the streets as well as in 'third places' (Oldenburg \& Brissett, 1982). Third places are separate from the usual social environment of home (first place) and work (second place). 
They vary by culture, and include spaces such as the French café, the Mexican street market or the English pub (Oldenburg, 1999). Third spaces provide the space for wellbeing-giving experiences and relationships to develop because people congregate in them to enjoy each other's company. This can take place directly, by starting conversations, or also indirectly, by enjoying the 'buzz' (Shaftoe, 2008). These ideas provide rich pickings for empirical work.

The theory of mattering, which is in its 'nascent stage' (Raque-Bogdan, Ericson, Jackson, Martin, \& Bryan, 2011), may be crucial in explaining the phenomenon whereby engaging with weak ties gives people a sense of wellbeing (Rosenberg \& McCullough, 1981). 'Mattering' is defined as the degree to which people feel that they matter to others. 'Mattering' theory has been used to explain the salience of social connection, how social connection offers wellbeing and what factors motivate social connection (Demir, Özen, Doğan, Bilyk, \& Tyrell, 2011; Thoits, 2011). The concept of 'mattering' consists of three components (Elliott, Kao, \& Grant, 2004; Racque-Bogdan et al., 2011). Firstly, that people need to feel that others are aware of them. This feeling derives from being acknowledged and attended to by others. Secondly, people need to feel that they are important to others, that others are invested in them and their actions. Lastly, people need to feel that others are reliant on them, that they are needed in some way (Elliott et al., 2004; Marshall, 2001). This last component emphasises the need to feel able to give, not merely receive, support in order to achieve wellbeing. According to this theory, only through connecting with others and featuring in other peoples' minds can people feel significant (Flett, 2018).

Mattering theory puts interpersonal relationships at the core of individuals' being and sense of self. This is in line with existentialist thinking, which purports that each individual is inextricably linked to others and cannot be seen as ontologically separate from the external world (Heidegger, 1978). Building on this, Fromm (1994) argues that we have a desire to 'belong' in order to avoid a sense of insignificance relative to everyone and everything around us. Social ties give individuals the security and rootedness they crave, as well as a way of creating connections and making meaning, at the expense of absolute freedom. This notion of absolute freedom that people deny themselves is also present in Sartre's philosophy where he writes that humans are 'condemned' to be free (Sartre, 2007). This 
freedom is linked to existential angst, which results from the thought that one is insignificant. Furthermore, 'mattering' is aligned with the demand for recognition, both of one's dignity as a human being, as well as one's uniqueness and difference (Honneth, 1995; Taylor, 1994). Both types of recognition require people to be open-minded and tolerant of other people and groups. This is achieved through civility in public life, by acknowledging and respecting each person as an autonomous entity with their own interests and goals (Buss, 1999). This brings to the fore the ethical links people are bound by, which are presented as dialogical and negotiated between people (Markova, 2016).

Is 'mattering' at odds with city living? Certain classical theories argue that city-life is characterised by social conventions that deny city-dwellers the opportunity to interact with others, leaving them anxious and alienated. For example, overload theory, put forward by Simmel (1903) and Milgram (1970), posits that people disengage from others in cities because they encounter more environmental stimulation than they are able to process. Simmel describes this as a blasé attitude that one adopts in order to psychologically and socially protect oneself from the crowds of strangers encountered day-to-day (Simmel, 2002). Similarly, Milgram (1970) argues that this harsh, unfriendly and aloof display of attitude is necessary in order to deal with the stimulus overload. Proshansky (1978), in a line of thought that is more pragmatic, argues that this attitude is merely a strategic way of social interaction that allows people to share a public space, without getting personal, which would be impossible given the sheer number of people encountered daily. In addition, these strategies are a way

of gaining control of one's space, protecting the self and not feeling threatened by the presence of strangers.

\section{Current study}

Given the contradictory social theories regarding how strangers interact with one another in cities either in an alienated or in a lively, effervescent way - and whether these interactions are wellbeing or ill-being inducing, it is timely to gather empirical evidence. Thus far it has been found that the power 
of 'weak tie' relationships is demonstrated via activities that are of a social nature, such as singing in a choir or playing an instrument, playing sport or going to church, which provide people with more positive affect than those of a non-social nature (Ascenso, Perkins, Atkins, Fancourt, \& Williamon, 2018; Pavot, Diener, \& Fujita, 1990). Moreover, volunteering to help others, with whom one has little intimacy, is associated with increased positive affect and meaning in life (Greenfield \& Marks, 2004). Even one-off interactions with strangers have been found to be wellbeing inducing. For example, simply taking the time to have a social interaction with a barista in a coffee shop increases a person's wellbeing (Sandstrom \& Dunn, 2014).

The expectation, based on the existing social theory, is that different contexts are associated with the more wellbeing versus the more ill-being inducing impacts of strangers. Such contexts include visceral settings where music/eating/drinking are to the fore versus those where overcrowding it to the fore, as on public transport. This study will utilise a social representations approach (SRA) to explore people's representations of strangers in their myriad contexts. A SRA provides a useful framework for this study as it focuses on how people represent unknown social entities (Moscovici (1961/1976, 1984). The stranger is, by definition, such an entity. SRA posits that the unfamiliar or unknown is anxiety provoking (Joffe, 1996). The unknown poses a threat since it jeopardises the individual's sense of mastery of a known world. While the expectation is therefore that feelings of threat are to the fore in representing the stranger, other currents within this approach show that all social entities are conceptualized in terms of themata. Themata are implicit, underlying structures of thought that play a key role in shaping how people conceptualise entities. Themata are usually formed of dyadic, interdependent opposites (Markova, 2015); an example of a thema (the singular of themata) is good/bad. The structure of the thema dictates that one cannot conceptualise one side - 'good', without having an idea of the opposite side - 'bad'. Furthermore, they are dialogical as people's representations shift between the two polarities, rather than being fixed. Themata are not immediately visible in the content of everyday conversation but underpin people's social representations or common sense thinking. Thus, they can only be captured by exploring the deeper social logic underlying the themes evident in common sense talk. 
A SRA study of how people in Britain's two largest cities conceptualise strangers will cast light on the structure and content of representations of the stranger, as well as the extent to which mattering theory can be applied to understand the intentions and motivations people hold towards wanting to connect with or disconnect from strangers. The research questions are:

1) How do city-dwellers represent strangers?

2) What contextual factors shape social representations of strangers?

3) What motivates city-dwellers to connect with strangers?

\section{Methods}

\section{Participants}

A sample of 96 London and Birmingham city-dwellers, previously studied for their city and personal aspirations (see Joffe \& Smith, 2016), were re-approached and asked to take part in this research. Social connection had been the dominant theme in their personal aspirations and this study sought to explore this theme in greater depth. Using contact details held by the recruitment agency, the researcher contacted previous participants via telephone between August 2016 and January 2017 to request participation. Only participants still living in London and Birmingham were eligible to re-participate. The researcher succeeded in recruiting an equal number of participants from London $(n=26)$ and Birmingham $(n=26)$.

Participants ranged from 21-70 years old, with 15 in the youngest age category (21-38), 18 in the middle age category (39-57) and 19 in the oldest age category (58-70). Age categories were based on the previous study of city-dweller aspirations, from which the sample was drawn (Joffe \& Smith, 2016). In terms of gender, 24 males and 28 females were interviewed. Of these participants, 30 were higher and 22 lower socioeconomic status, according to a social grade system based on type of occupation, used by the Office of National Statistics (UK), among other organisations (Ipsos, 2009). Lastly, 34 participants identified as White British and the remaining 18 as British Minority Ethnic (BME). 
Figure 1 City-dweller demographics

\section{Procedure}

Participants were recruited following receipt of ethical approval. Before the interview commenced, the interviewer provided all dwellers with an information sheet outlining the nature of the study: a research project to explore people's thoughts on social relationships in the city. All participants signed a consent form agreeing to be interviewed and audiotaped; they were assured that confidentiality and anonymity would be upheld.

The Grid Elaboration Method (GEM) (Joffe \& Elsey, 2014) was used. The GEM aims to elicit subjectively relevant material with a minimum of researcher interference; it seeks to elicit 'stored', naturalistic ways of thinking about an entity (Joffe, 2012, p. 213). The method consists of a free association task followed by a subsequent interview in which participants elaborate their free associations. In accordance with the GEM, participants were asked to complete a free association task before each interview ${ }^{1}$, which elicited their free associations regarding "interactions with strangers and acquaintances in the city". This was followed by an interview in which they elaborated their associations. An example of a grid is given in Figure 2.

Figure 2. Example of weak ties grid

When participants were asked to elaborate fully on their free associations with prompts such as 'could you tell me more about that', the interviewer was careful not to use any words that were not first used by the participant, to minimise researcher-led content in the interview. Interviews on these

\footnotetext{
${ }^{1}$ Dwellers were also presented with another grid asking for their "experiences of friendship" in order to capture this form of social tie. However, this is not presented in this paper. The associations to acquaintances were also separated out so that only the analysis of associations to strangers are presented in this paper.
} 
free associations lasted an average of 19 minutes. After the interview, each participant completed a survey that asked for demographic details. They were then debriefed on the purpose of the research interview.

The grids were scanned and the audio recording of the interview was subsequently transcribed verbatim and imported into the ATLAS.ti software package for analysis.

\section{Data analysis}

A thematic analysis of the interview data was performed (Joffe, 2012; Joffe \& Yardley, 2004). The codes were inductive, based on the patterns evident in the data. In order to assess reliability of the codes, 9.6\% $(\mathrm{n}=5)$ of all interviews were independently coded by one of the authors and an independent researcher. To evaluate inter-coder consistency, the two sets of codes were compared. Inter-coder reliability was achieved with an average Kappa of 0.66, indicating 'substantial' (Landis \& Koch, 1977) reliability. Discrepancies were resolved and the coding frame revised following discussion between coders in line with the process laid out in O'Connor and Joffe (2020). All interviews were then coded using the revised coding frame and Atlas ti software.

Once all transcripts were fully coded, a number of tools and strategies were utilised to capture the meaning of the data and prevalence of the themes. Finally, codes were investigated for demographic differences (i.e. gender, age, socio-economic status, city of residency and ethnicity), in order to capture who espoused which representations of strangers. Demographic differences are reported where found. ${ }^{2}$

\section{Results}

The thematic analysis indicated that conceptualisations of strangers were characterised by being 'good' or 'bad'. The 'good' stranger is one that is friendly, supportive, interesting and a potential strong tie. The 'bad' stranger is conceptualised as dangerous and rude. These conceptualisations are impacted by three contextual factors: place, time and technology. This is elaborated below.

\footnotetext{
${ }^{2}$ Demographic differences reported are observable differences in relative prevalence of the code in the different groups.
} 


\section{The 'good' stranger}

'Good' strangers were referred to by over three quarters (77\%) of the participants and were conceptualised as: 1) friendly (71\%), 2) vulnerable (52\%), 3) potential friends (29\%) and 4) interesting (23\%). These categories, and indeed those mentioned in the 'bad' stranger section, were not mutually exclusive.

Figure 3. The 'good' stranger

\section{The friendly stranger}

The friendly stranger is characterised by being warm, having a happy demeanour and providing pleasant and enjoyable interactions. BME participants were more likely than White participants to characterise strangers as friendly. Interacting with friendly strangers made everyday necessities, such as taking children to school, commuting, working or grocery shopping more enjoyable. Friendly interactions improved routine experiences and made one feel connected:

If you're in the supermarket and someone says hello or, you know, it's just nice to have that interaction, you know. And again you get to know the postman, you go 'oh anything for me' or 'have you got this for next door' and it's just nicer than just dropping it through the door, yeah, makes you feel you've got that sort of connectedness (Female, 58-70, lower SES, White, London)

Friendly strangers were characterised by their smile, which was seen as a natural, positive and human gesture. It made people feel like 'the world is full of nice people'. It had the ability to cheer people up if they were not having a good day. It was seen as the antidote to many 'horrible things' that go on in the world, such as violence and war, as well as everyday family and financial stressors. Smiling 'doesn't cost a thing' and exchanging smiles was seen as something that helps one get through the day. 
A smile could also act as a conversation opener and could lead to pleasant chats with strangers, which was a way to 'spread joy'.

Smiling was also seen as a positive form of acknowledgement:

I just think it's a friendly thing to do and I don't know, it just gives people a sense of well-being I think, just being acknowledged, I think it's always nice if someone says hello to me walking down the street so I do the same. It can't cause any harm but it can be positive so that's how I view it (Male, 58-70, lower SES, White, Birmingham)

This excerpt demonstrates the wellbeing giving qualities of being smiled at. The smile represents care, acknowledgement and feelings of comfort and warmth from the other person.

Beyond smiling, other small gestures also showed that one has been noticed by a stranger and that one was being thought of, even in a minor way, such as someone 'press[ing] the lift button ... or hold[ing] the door open' for one. These were conceptualised as little acts of kindness that made one feel good because they recognised and valued one's existence and demonstrated respect. Furthermore, they made one feel accepted by others, which gave one a 'boost'.

Friendliness was seen as something that is universal and not affected by social hierarchy.

But it's just even with learning mentors or the cleaner, you say hello to them in the morning or, hiya, bye, thanks very much, care-taking staff, you just, you have a chat with them, everyone's important, it's just to say hello, you can't ignore someone as they walk past. Or, you know, as you're walking past them, if they look like they want to talk more you stop and chat and if they don't you just carry on... Just be nice to everyone (Male, 39-57, higher SES, White, Birmingham)

Being friendly towards others was associated with being respectful and polite. However, when discussing friendly strangers, comparisons were made with other types of strangers: 
There are a lot of bad people about but the vast majority of people are really, really nice. When I say the vast majority it's probably $99.9 \%$ are lovely (Male, 58-70, higher SES, White, Birmingham)

Thus, the friendly stranger was conceptualised in light of awareness of its opposite, though its opposite was represented as less prevalent by a sizeable portion of the sample.

Lastly, the benefit of friendliness when interacting with strangers in the city also extended to awareness that one should adopt a friendly attitude towards others:

Yeah I always make sure that um, whenever they walk away they're like gosh isn't she really friendly. Doesn't she have good manners? Wasn't she really really nice? And that's my mission (Female, 39-57, lower SES, White, Birmingham)

Being friendly and polite to strangers was regarded as even more important than being friendly and polite towards people one knows, like family and friends. It served to put people at ease and contributed to creating the positive and pleasant shared environment that people wished to experience in the city.

\section{The vulnerable stranger}

The vulnerable stranger refers to the people encountered in the city who were conceptualised as struggling or in need of help. BME participants were more likely to characterise strangers as being in need of support. City-dwellers talked about the need to wander around the city with open eyes, taking notice of those around them. There was a general sense that the first step to being of assistance to someone else is to be aware that they exist:

if somebody fell over in front of me, if someone was hurt in front of me, I could not walk away from that person... I couldn't ignore somebody in need. And maybe if everyone was just a tiny little bit like that ... if you made sure that person was all right (Female, 39-57, lower SES, White, London) 
Helping someone was a way of making a contribution and of being 'worth something in this world'. City-dwellers spoke of how it is nice is to be a 'Good Samaritan' and that being needed by others makes one feel good. Small acts of kindness were regarded as not particularly time-consuming but highly rewarding. A common example was helping homeless people who live in the city. There was a feeling that if everyone were more willing to help people, the world would be a better, happier place: ...people need to be aware of giving to anybody, it's important, not just their family members, not just their friends, to anybody (Female, 39-57, higher SES, BME, Birmingham)

Older people were a group often seen as strangers in need of support. The fast pace of city life was seen to render them vulnerable and at risk. Children were also represented in this vein. Ultimately, there was a shared reciprocity principle aired in that being helpful to people was seen as a good way of interacting because one would want others to do the same.

In contrast to this widely shared idea of strangers sometimes being vulnerable, a few participants referred to being vulnerable themselves:

I was stranded on the motorway one time and I think I phoned everybody in my family to come and get me and not one of them picked me up. But then somebody driving down the motorway seen us and dropped us to the nearest service station where we could get a lift... I phoned about a million people including friends and family and like I can't expect people to sometimes to drop everything that they're doing to come and get me but somebody who you don't know, say mate I'll drop you up there (Male, 21-38, lower SES, BME, Birmingham)

Overall, the data pointed towards a shared idea that 'nothing [is] as sweet as the kindness of strangers'. Acts like the one shown in the excerpt above made people feel like the world is a nice place, full of 'genuinely good people' and that people wanted to receive support and be 'good' to others. 


\section{The potential friend}

Strangers were also seen as a potential pool of people to draw from if one wanted to meet new people. As one participant said, no one would ever get to know anybody new if they did not talk to strangers. This conceptualisation of a stranger was one where an unknown person is 'just a friend you haven't met yet'. This cliché was repeated by many participants across demographic groups.

Meeting new people was viewed as fun and enjoyable, and could happen when one was out in the evening, having a good time. The fun resulted, in part, from the spontaneity and unplanned nature of these encounters. They happened when one was relaxed and felt open concerning where the conversation might lead.

Strangers were represented as becoming close ties through conversations. To initiate this, certain 'ice breakers' were deemed helpful. Sometimes, all that was needed was a smile and a friendly attitude or even 'cracking a joke' that puts people at ease. However, the most frequently mentioned ice breaker was having a dog. This was seen as a useful way to meet people because when walking the dog, people start conversing about the dog and one may find oneself 'standing there for 45 minutes' chatting to a stranger. Children were also seen to serve as good ice breakers, particularly when two adult strangers are looking after their children when encountering one another. This was linked to children being more open to making contact with other children and wanting to play, thereby bringing the adults into an encounter. Furthermore, having children or pets was seen as a shared, non-threatening experience over which adult city-dwellers could chat and bond.

Lastly, alcohol was deemed a way of breaking the ice and rendering one more open to strangers by making one feel at ease:

I met a lot of my friends from when I was doing that clubbing stage of my life, and they are people that I'm friends with now and, you know, you're obviously drunk and you speak to strangers then but sober on a Tuesday queuing up in a post office, you don't want to be talking to someone in there (Male, 21-38, higher SES, White, London) 
Dogs, children and alcohol were conceptualised as ice breakers that facilitated interactions that would not otherwise occur.

\section{The interesting stranger}

The interesting stranger was the unknown person that intrigued city-dwellers. Men were more likely to characterise strangers as interesting. Interesting strangers were seen as life-enriching and interaction with them, even via a smile, was viewed as a 'ray of sunshine'. Interesting strangers were a source of variety and diversity. Speaking to people from different social and cultural backgrounds was particularly valued; it allowed city-dwellers to learn about cultures, countries, languages and outlooks different from their own. Cities were regarded as particularly good for this as they bring together a variety people. Interesting encounters also derived from talking to people of different age groups:

Sometimes if a couple of young people are going into the train, into Birmingham on the train, speak to them, ask them where they're going, anywhere nice, and they just say yes we're going to blah-di-blah nightclub or music or whatever and they'll laugh that you're interested ... and you've made these little friends, it might not be a lifetime relationship but when the train pulls in at the city centre you can go your way and they can go theirs and hopefully they will have enjoyed your company and you probably enjoyed theirs (Male, 58-70, higher SES, White, Birmingham)

These conversations were deemed rewarding. People wanted to talk to interesting strangers, learn about them, or even watch them and wonder about them (i.e. people-watching on the bus) to satisfy their 'natural' curiosity. Meeting new people at work was also a way to make work more enjoyable as new people 'bring new life', fun and energy to a situation:

And you might learn something because people like to have conversations sometimes, they're not robots, they don't just want to have the answer and move on, they want to, you know, that exchange of information is kind of like if they've got information from you, say for directions, 
they might want to give something back and say oh by the way I really recommend, I don't know, the ice cream over there or something (Female, 39-57, higher SES, BME, London)

An interesting stranger was associated with unpredictable and spontaneous positive moments. This brought with it an element of surprise and a sense of novelty, which city-dwellers enjoyed.

\section{Contextual factors that shape the representation of a stranger as 'good'}

Three contextual factors impacted on positive representations of strangers. These were place, time and technology. Certain places were associated with 'good' strangers. For example, sports matches were highlighted as spaces in which these interactions prevail. This was attributed to a sense of camaraderie and community feeling because a group had come together for the same reason. This created an environment where everyone laughs and has a good time. Even if one's team was losing, the sharing of the experiences and the sense of togetherness made it more enjoyable. Shared interests also made it easy to start conversations with people.

Interactions with strangers also took place in shops or outside of the city, for example on holidays. Meeting people and exchanging stories with them was seen as a way to enhance a holiday, learn and get to know a place better and make experiences more memorable.

This was linked to city-dwellers' representations of time, which people felt they had more of on holiday. Taking 'time out' was associated with being relaxed and thereby having more time to interact with strangers. Other settings, such as clubs and bars, as well as parks, were also associated with having more time to talk to strangers. Here having time to speak to people in enjoyable surroundings added fun and novelty to one's experience of the city:

If you're on a night out, you're at like a bar or a restaurant or a nightclub or whatever, you want to talk to those people more probably because you have nowhere to be, you're in a social setting. But then there are different like circumstances so you could be in a park ... that would 
be a daytime version of where it wouldn't be rushed (Male, 21-38, higher SES, White, Birmingham)

Beyond place and time, technology could facilitate a positive meeting with strangers whom one would otherwise not come across. Technology allowed participants to meet people with similar interests and backgrounds even if they were not in one's immediate physical environment:

Yeah I would say I was in a relationship recently, for the last 6 months, it ended so my barriers went up and that's when I joined Tinder just because it's hard because when you're working long silly hours it's hard to basically meet people (Male, 21-38, higher SES, BME, London)

For a minority of participants technology was a means to turn strangers into potential friends or partners. New apps that were designed to facilitate meetings with others similar to one were seen, particularly by younger city-dwellers, as a more efficient ways of meeting strangers than going out in the city. However, even those who espoused the benefits of technology in connecting them with strangers did not think of technology as a substitute for face-to-face connection, which was viewed as a 'proper social interaction'; technologically mediated interaction was seen as a lower quality interaction when compared to face-to-face.

\section{The 'bad' stranger}

The 'bad' stranger was mentioned by almost three quarters (73\%) of participants and could be divided into two subthemes: 1) the dangerous stranger (50\%) and 2) the rude stranger (35\%). These two types evoked a range of negative emotions, including fear, discomfort, anger and annoyance.

Figure 4. The 'bad' stranger 
The dangerous stranger

Dangerous strangers were seen as untrustworthy due to their potential to be violent or harmful. Citydwellers, men and women equally, were wary of and afraid to interact with dangerous strangers and so avoided them. Lower SES dwellers expressed this type of conceptualisation slightly more often than higher SES dwellers.

Within this representation of the 'bad' stranger participants focused on the uncertainty and possibility that an unknown person could have bad intentions:

you distrust them 'til you know them, you don't trust them 'til you know them. I think one would be very stupid to trust a total stranger (Female, 21-38, lower SES, White, London)

There was a shared conceptualisation that there were not many cues available when assessing whether an unknown person was dangerous or not. A key source of information was their physical appearance - what they are wearing or whether they looked hygienic:

... you're meeting a stranger, maybe they are not as hygienic as you are, you perhaps think that's not a good person. You don't know... they might have been a drug user in the past or something like that and they've got mental issues ... it can put up a bit of a barrier... Wrongly or rightly (Male, 58-70, higher SES, White, Birmingham)

Another source of information was the behaviour that could be observed. Strangers lingering in public spaces, particularly at night, made dwellers suspicious and evoked worry that they might be dangerous:

... you don't know these people ... you've never met them before so you just don't know if they've got a knife ... are they going to threaten you? (Female, 58-70, lower SES, White, Birmingham)

Dwellers were generally on high-alert when it was dark and worried if someone walked too close to them, or too slowly. Other behaviours indicative of a dangerous stranger were those deemed anti-social. Young people were the particular group associated with this, which included drinking, shouting, 
smoking, littering, playing loud music and swearing. These behaviours made city-dwellers wary and fearful. Furthermore, dwellers talked about displays of 'mad' or drunken behaviour - for example people talking to themselves - which scared them. However, there was a conceptualisation that this information was insufficient to make a correct judgement and that one can never be sure of who was dangerous and who was not, because 'a bad person can come with a smile on their face'.

Interactions were circumvented by deliberately avoiding eye contact, keeping 'themselves to themselves'. Some wore their wariness as a 'suit of armour' and were very guarded. If dwellers had to talk to someone, they kept conversations 'very brief' and did not reveal too much about themselves. This form of disconnection acted as a safety mechanism.

They talked of this fear being instilled at a young age; it was commonly referred to as 'stranger danger':

As in like you're taught in schools, obviously they teach that to the little children and saying 'keep away from strangers', obviously strangers are like out and forcing children to take sweets and all that and then obviously kidnapping them so it's been built in at a young age, yeah, to keep away from them (Female, 21-38, higher SES, BME, Birmingham)

Strangers that seemed too interested or 'too friendly' were conceptualised as 'strange' and potentially dangerous. Participants explained that they did not know what people were capable of and that thoughts of people harming them or their family would 'creep' into their mind in a way that was insidious.

\section{The rude stranger}

The second negative characterisation of strangers was that of the rude stranger. This type of stranger displayed inconsiderate and selfish behaviour towards others and was not someone one wanted to meet in the city. Londoners talked about rude strangers slightly more than Birmingham dwellers. Unlike with the dangerous stranger, the rude stranger was not associated with uncertainty or seemingly unlimited negative consequences. Instead, the rude stranger was represented as rude because of their behaviour. This was linked to emotions of annoyance and anger, rather than fear. It was associated with a belief 
that people did not care about others, that they were selfish and inconsiderate and were only interested in themselves:

I think the majority of people just don't care about people around them and the environment around them, which is sad, very sad (Female, 39-57, lower SES, White, London)

This was partially attributed to lack of resources. A London-based example of this was lack of space on the underground. Here strangers were just looking out for themselves, occupying space and trying to dissociate themselves from the many people around them. The underground was portrayed as quite a 'nasty' environment because people pushed, barged past and knocked others over:

They try and push, they try and get in, they'll be all for themselves and not for anyone else and it is that their time is so, so precious to them that they've got to spend every moment of it looking after themselves and they don't seem to care about anybody else (Male, 39-57, higher SES, White, London)

Rude behaviour was also linked to the expectation of immediate gratification. The rude stranger was impatient and got annoyed. Annoyance was displayed by rude glances, 'like the piercing stares', the 'raising of the eyebrows' or 'sighing'. In extreme cases, this led to aggression, as seen in road rage.

Rude behaviour was seen as having increased in recent years, which was deemed to have affected people's local areas in negative ways. A number of dwellers mentioned that their areas used to be 'quiet' and 'pleasant', but were now crowded with people who walked 'like a herd of elephants' pushing and shoving and stepping over people if they had to, rather than helping others. This was particularly prevalent in London where such behaviour was seen as the norm because it was so common. Dwellers noted that one would not expect an apology if another person ran into one and that Londoners were used to this behaviour. They compared this behaviour to how people behaved in smaller towns and villages, where people were seen as friendly and kind to one another; they imagined that those people would be shocked or even 'traumatised' by how Londoners interacted with each other. 


\section{Contextual factors that shape the representation of a stranger as 'bad'}

The representation of the 'bad' stranger was shaped by place, technology and time. Places in which there were not many people, or with low visibility, such as a dark city street at night, were associated with dangerous strangers. On the other hand, busy transient spaces, such as a tube/train or a busy pavement were associated with rude strangers. These were places people did not like to be in but had to be in to get to where they wanted to go.

This was linked to the use of technology since technology was seen as a way of disengaging from a place one did not want to be in. The amount of attention paid to technology was associated with a negative impact on social interaction with strangers, particularly by those in the middle (39-57) and older (58 - 70) age group. Rudeness was frequently attributed to advances in technology. Most notably, people mentioned the impact of the mobile phone. Rude strangers walked through the world with 'blinkers on', oblivious to what was happening around them. They did not take notice or show interest in others, even if another person needed help. People were deemed too busy to help others and were seen to not care. Such behaviour was attributed to young people. The young were seen as people who had not been raised to respect others, did not know how to hold a conversation and acted as if the 'world owed them something'. Youth was associated with selfishness and preoccupation with one's own life. Technology was also attributed with the ability to isolate people from one another: Focusing on technology instead of people around one was seen as a way of disengaging from one's environment and was deemed rude and anti-social. The most common device mentioned in these terms was the mobile phone, which people were 'glued to'. One thing seen as particularly rude was being on the phone whilst interacting with another person:

You're having a sort of interaction with the girl behind the till or the lad behind the till, it is so rude just be, you know, ignoring them and talking to other people (Female, 58-70, higher SES, White, Birmingham) 
Being on the phone was also associated with rudeness because it showed that people were not interested in others, only in themselves and their own world:

I'm aware of my surroundings and I do take other people's opinions into consideration but I feel that there's so many people that are so inconsiderate ... people walking along the street just looking at their mobile phone and expecting other people to move out of the way of them... (Female, 39-57, lower SES, White, London)

There was also a sense that technological innovation could lead to a society in which no one talked to strangers anymore. This was seen as particularly damaging to fulfilling people's social needs:

Digital economy again, it is dehumanising. ... anything I want now, going back to this, I don't have to speak to anyone, I just go on Amazon, it will be on Amazon, whatever you want, even food now. And you don't have to speak to anyone (Male, 58-70, lower SES, White, London)

Beyond technology and place, a third contextual factor, lack of time, was most prevalent in the conceptualisation of strangers as rude. As time was seen as a resource, spending your time with people was seen as an investment. Spending time with strangers - people you do not know- was a risky investment because one did not know whether one would like them and this risked it being a waste of time. Getting stuck in a conversation with someone for longer than desired was seen as negative. Someone else 'may have all the time in the world', but busy city-dwellers felt they did not. Lack of time was not only experienced on an individual, but also on a city, level. This was epitomised by discussion of the 'hustle and bustle' of the city, which left people with 'no time to talk'.

A different facet of time shaping people's conceptualisations of dangerous and rude strangers was the 'past'. There was an overarching sense in the data that the world had changed and that it had become a 'more complicated' and 'darker' place:

... you just don't know who you are saying hello to and what their motives are. Not everyone is nice anymore (Male, 39-57, lower SES, White, Birmingham) 
This fear led to a society where children no longer played on the streets or went anywhere alone, whereas in the past children took the bus alone and 'nobody batted an eyelid'. Society was represented as more dangerous than it used to be; this was related to the state and other social institutions not holding people to account:

The police have got no power, parents have no power, teachers have no power. Which is unfortunately bringing up a load of disrespectful gits ... I believe, I was brought up right. If I misbehaved the teacher would give you a clip round the ear. If you misbehaved the police would give you a clip round the ear and send you on your way and if that happened you would go home and your mom and dad would give you a clip round the ears just for being in trouble so. And that doesn't happen anymore. Because of you know, it's not nice. But it worked (Male, 39-57, lower SES, White, Birmingham)

This lack of respect and manners was epitomised in what was seen as the demise of 'common courtesies' like holding the door open for a stranger; these were said to be absent in the present city. In particular the youth were seen as having been raised to be 'feral', 'arrogant', 'entitled' or even criminal.

This was contrasted with the behaviours of older people, those raised in 'the past', who were seen to be chattier and more likely to interact with strangers in a communal, friendly and courteous manner. This idea cut across the different age groups. Younger dwellers, who did not have their own personal experiences to refer to, made reference to stories they had been told by their elders, such as parents or grandparents.

There was a strong association between 'the past' and 'place' factors. People's local area was seen to be less salient to them in present times, and so people lacked local shops or services in which they were familiar with the staff and connected to them. This was also related to demise of community in contemporary city living:

Apparently in the war everybody, in the second world war everyone used to speak to everybody (Male, 58-70, lower SES, White, London) 
Newspaper vendors to my mind go back almost to black and white films, they're always there outside the station, outside the Tube station, going "E'en Standard, Standard!" And of course they see a lot of the same people every day and so they go, here you are, how's the wife, you know, couple of oranges for her (Male, 58-70, lower SES, White, London)

These quotes demonstrate that participants felt that social interactions with strangers in the past were not constrained by technology and a lack of time and so facilitated more favourable and pleasant connectedness with others in the city.

\section{Discussion}

\section{Social representations of strangers}

The results illustrate that strangers are represented as 'good' or 'bad' in cities. On the one hand, strangers are represented as friendly people who make life in the city more enjoyable. They are seen as good and interesting, worthy of kindness and support. One can learn from the stranger and may want to get to know the stranger further. On the other, strangers are conceptualised as dangerous and fearinducing and therefore best avoided, or rude and annoying people that cause discomfort and frustration.

The context in which strangers are encountered impacts people's representations. In particular, technology, place and time shape how strangers are conceptualised. The role of place is particularly salient. The 'friendly' stranger is often conceptualised as someone met in a semi-public spaces, such as a shop or sports stadium. This setting makes people feel they have something in common with the stranger, making the stranger less unknown and unpredictable. This, in turn, produces feelings of safety and facilitates opening up and 'letting your guard down' in order to engage in positive social interactions. The spatial element in the data is in line with the notion of third places, put forth by Oldenburg (1999), which are semi-public in nature and facilitate interactions that are intrinsically enjoyable. Furthermore, it corroborates previous research on 'collective effervescence' in which people crave the 'joy of association' (Gabriel, Valenti, Naragon-Gainey, \& Young, 2017; Jacobs, 1961). 
In contrast, the 'dangerous' stranger is often associated with public spaces, such as streets, particularly at night. Open space, as well as darkness, makes people feel less in control of their environment and therefore more vulnerable, which leads to feeling alert and suspicious of others. This, in turn, is associated with uncertainty and the possibility that anything could happen. This shows that one of the factors leading to social disconnection from strangers in the city is fear for one's physical safety and that this propels people to ignore others in the city. This corroborates Proshansky (1978), who argues that these avoidance strategies are ways of gaining control of a space, protecting the self and not feeling threatened by others.

A further aspect of place that negatively affects interactions with others overlaps with time as an important contextual factor: the busy and hectic environment is one in which the rude, rushed and apathetic stranger is encountered. This representation was particularly salient in the London data. However, apathy forms part of dwellers' representations of other people's orientation towards fellow dwellers, not their sense of their own orientation towards others. This is different to the 'dangerous' stranger where participants report actively wanting to disengage. This distinction highlights the benefit of examining social representations of strangers, rather than relying on observational studies as found in past research (Goffman, 2009; Milgram, 1970). It highlights the distinction between feelings and orientations towards strangers that people claim for themselves as opposed to conceptualisations that they see other people holding.

Furthermore, when dwellers feel they have time to engage with strangers, they conceptualise them as 'good' people who are friendly and interesting. By way of contrast, lack of time due to being busy is linked to disconnection from strangers. This corroborates research indicating that lack of time hinders connection with weak ties (Levine \& Norenzayan, 1999). Furthermore, the findings are in line with theory that sees modern capitalist Western societies as focusing on having and producing as the key to a good and happy life (Giddens \& Pierson, 1998; Liu, 2006; Wajcman, 2015).The aims of having and producing hinder elements of social connection that are not transactional or materially-based such as fleeting interactions with strangers. 
Rude strangers are not only associated with particular places and rushing, they are also linked with technology. When approached naturalistically, without prompting, the stored reaction regarding how technology impacts connectedness is primarily negative in this data. It is deemed to distract people as they move through the city, which causes irritation. Technology is seen as a way of people distancing themselves from strangers and their current physical environment. This is in line with the contentious work of Turkle (2015), which sees the mobile phone, in particular, as a barrier to connection with people, as it hinders the level of engagement with those around one.

This study not only highlights the content of the social representation of the stranger in the city, but also the underlying social logic that determines the way in which the stranger is conceptualised. More specifically, the data show that representations of strangers are based on a number of themata. In particular, conceptualisations of strangers in the city are shaped by the good/bad thema. The unknown person or stranger is made sense of through the interdependent representations of 'good' and 'bad'. Representations of strangers as 'good' include the qualities 'friendly', 'supportive' and 'interesting'. In contrast, representations of strangers as 'bad' are constituted by their 'danger' and 'rudeness'. Being able to move between polarities, as half the sample does, points to the dialogical nature of commonsense thought. When this movement in thinking happens, it is linked to the deeper underlying self/other thema, where 'good' is associated with self, and 'bad' with other.

This is most evident in city-dwellers' discussion of the 'friendly' stranger. More than any other representation, the discussion of this type of stranger switches between representations of strangers and representations of self. Furthermore, the sense that others also see one as a stranger is only present in the representation of the 'good' stranger. By way of contrast, 'bad' representations of strangers are seen as not containing qualities possessed by the self. For example, the 'dangerous' stranger acts in ways that are different from self; the behaviour displayed cannot be explained with reference to known behaviour. This not knowing results in uncertainty and is linked to fear. Furthermore, the 'rude' stranger is 'other' in that s/he breaks the rules and norms that participants value and attribute to self.

This study shows that strangers, by definition unknown 'other' entities, are as likely to be positively as negatively represented depending on whether one identifies or dis-identifies with them. 
This is at odds with other studies of the self/other thema (see Smith, O'Connor, \& Joffe, 2015) where 'the other' tends to be associated with negative affect. Imbuing representations of self with positive emotions, and representations of others with negative emotions is regarded within the social representations literature as a way of protecting the self by pushing negative emotions away; from the earliest years of life representations linked to self are associated with positive emotions and those to others with negative emotions (Joffe, 1999). This does not hold in the study of strangers. 'Dangerous' and 'rude' strangers are cast as threatening. The other types of stranger - 'friendly', 'vulnerable', 'interesting' and 'potential friends'- to varying degrees, are seen to offer the potential for positively valenced social connectedness.

\section{The desire to 'matter' as motivation for connecting with strangers}

The fundamental human motivation for social connection is demonstrated in this study. Beyond the desire to connect with strong ties, city-dwellers are motivated to connect with 'good' strangers encountered in the city. The data show that friendly and pleasant interactions with strangers are important to city-dwellers and an absence of such interactions hinder the sense of wellbeing. In particular, small scale, face-to-face, pleasant interactions wherein people feel acknowledged are highly valued. This is because such interactions are associated with a 'basic level of care' predicated on an acknowledgement of a shared humanity. The smile, in particular, is a symbol of warmth, which is associated with care and gives people a sense of the world as a good place. Moreover, receiving support from strangers shows that one is important enough that others would offer assistance, just because they are human. This is exemplified in the notion of the 'kindness of strangers' and provides dwellers with a sense of security. This acknowledgement echoes work by Taylor (1994) who deems a key aspect of a just society to be respect for other people based solely on the fact that they are human beings; this is achieved through civil and respectful behaviour. However, the data indicate the need to go one step beyond simple civility, by exposing people's desire to experience warmth and care for others. These forms of care, acknowledgement and awareness, in line with existentialist thinking, are ways to relieve anxiety (Lacan, 1997; Sartre, 2007). Thus people's motivation to connect with strangers are shaped by 
a desire to 'matter': Dwellers want to enter the awareness of and be known by others, be relied upon by them and feel important to them (Elliott et al., 2004).

In the city, not being seen - having a door shut on one - makes dwellers feel they do not matter. The ill-being described in the data as a result of being ignored or not having human contact is further evidence of the importance of mattering; experiences of being overlooked or ignored trigger anxiety that one is insignificant and that no one would notice one's absence (Fromm, 1994; Sartre, 2007). This highlights that lack of acknowledgement is not just a missed opportunity for a positive experience, but actively creates negative experiences that foster city-dweller ill-being. This again ties in with work on the politics of recognition (Honneth, 1995; Taylor, 1994), as this type of behaviour does not acknowledge others as autonomous beings with their own individual needs and goals.

Being of assistance to others in the city allows people to feel needed, which is linked to the concept of reliance in the theory of mattering. It is a way of adding value to the world one inhabits and is, again, a way of ensuring one is not insignificant. This shows that city-dwellers are motivated to engage and notice others as a way of feeling 'of use' to others and thinking well of themselves. This is linked to self-esteem, the area of research from which mattering initially developed (Flett, 2018). This study adds to the literature on motivation for connection by highlighting the importance of giving, rather than receiving support. It thereby elevates the role of giving support, which is usually seen as secondary and less important than receiving it, as well as providing an existentialist explanation for why providing support is so important for wellbeing-giving social relationships.

Lastly, the desire for social connection with strangers is also motivated by enjoyment. Even when talking about services in cities, face-to-face connection is not aspired to because it is seen as more efficient, but because it is regarded as more pleasant and enjoyable. In line with Jacobs (1961) and Simmel \& Hughes (1949), these aspirations point to a conception of the city as a place of 'collective effervescence' - a state in which joy is felt by the sheer presence of the other. This idea of visceral joy makes the case for extending mattering theory to account for the physical and emotional, rather than the purely cognitive elements, which motivate social connection. Furthermore, by bringing together mattering theory with other more established theoretical traditions, such as existentialism and the 
politics of recognition, this study begins to add theoretical depth to the theory of mattering. Lastly, it extends its reach by showing that the desire to matter is so deeply human that it even characterises interactions with strangers.

\section{Limitations and future research}

This study explores a particular cultural and societal context, that of the large British city, and as such caution must be applied in generalising its findings. Though the desire to matter to others has been shown to exist across cultures (Flett, 2018), the way in which this applies to strangers, as well as how this manifests in people's representations, is likely to differ. Replicating this study in a different societal context, for example a non-Western collectivist culture, would provide a fascinating insight into the differences and similarities. Another limitation of this study is its lack of triangulation: using multiple methods to develop a comprehensive understanding of a phenomenon (Patton, 2002). Although the qualitative nature of the study makes a valuable and unique contribution to the mattering literature, gauging mattering quantitatively via the established measures (See Elliott et al., 2004; Marshall, 2001) would have provided triangulation. Such work would also be able to capture individual differences that might impact the way in which strangers are conceptualised. For example, people's individual attachment styles (Mikulincer \& Shaver, 2007) may be significant and would be a valuable avenue for future research.

\section{Implications}

This study has two clear implications for future city design and policy. Firstly, it can be applied to designing city spaces in such a way that they foster rewarding social connection between strangers. In particular, it shows that city spaces need to be designed to be more than just functional arenas in which services can be accessed. Spaces need to allow people to have fleeting positive interactions, to acknowledge one another in small ways and to show interest in each other whilst going about their daily lives. Furthermore, places in which similarities, such as shared interests, are visible and can become known are best placed to foster connections with strangers as these reduce uncertainty and fear. This includes semi-public events, such as sporting and music occasions, where people come together on the 
basis of a common interest. Secondly, the importance of mattering has an impact on the types of services offered in cities. The findings presented in this paper challenge the current emphasis on 'smart' services that prioritise speed and efficiency, such as self-checkout desks. Such services factor out the human desire to connect and matter to other humans.

\section{Acknowledgements:}

This research was funded by the EPSRC (Engineering and Physical Sciences Research Council) grant Transforming the Engineering of Cities to Deliver Societal and Planetary Wellbeing no. EP/J017698/1. The Principal Investigator of the overall project was Christopher Rogers, University of Birmingham. 


\section{References}

Ascenso, S., Perkins, R., Atkins, L., Fancourt, D., \& Williamon, A. (2018). Promoting well-being through group drumming with mental health service users and their carers. International Journal of Qualitative Studies on Health and Well-being, 13(1), 1484219. doi:10.1080/17482631.2018.1484219

Buss, S. (1999). Appearing respectful: The moral significance of manners. Ethics, 109, 795-826.

Demir, M., Özen, A., Doğan, A., Bilyk, N. A., \& Tyrell, F. A. (2011). I matter to my friend, therefore I am happy: Friendship, mattering, and happiness. Journal of Happiness Studies, 12(6), 9831005. doi:10.1007/s10902-010-9240-8

Diener, E. (2012). New Findings and Future Directions for Subjective Well-Being Research. American Psychologist, 67(8), 590-597. doi:10.1037/a0029541

Diener, E. (2013). The Remarkable Changes in the Science of Subjective Well-Being. Perspectives on Psychological Science, 8(6), 663-666. doi:10.1177/1745691613507583

Diener, E., \& Seligman, M. (2002). Very happy people. Psychological Science, 13(1), 81-84. doi:10.1111/1467-9280.00415

Diener, E., Suh, E. M., Lucas, R. E., \& Smith, H. L. (1999). Subjective well-being: Three decades of progress. Psychological Bulletin, 125(2), 276-302. doi:10.1037/0033-2909.125.2.276

Dolan, P., Peasgood, T., \& White, M. (2008). Do we really know what makes us happy? A review of the economic literature on the factors associated with subjective well-being. Journal of economic psychology, 29(1), 94-122. doi:10.1016/j.joep.2007.09.001

Dunn, E. W., Biesanz, J. C., Human, L. J., \& Finn, S. (2007). Misunderstanding the affective consequences of everyday social interactions: the hidden benefits of putting one's best face forward. Journal of personality and social psychology, 92(6), 990-1005. doi:10.1037/00223514.92.6.990

Durkheim, E. (1951). Suicide: A Study in Sociology. Glencoe, Illinois: The Free Press.

Elliott, G., Kao, S., \& Grant, A. (2004). Mattering: Empirical validation of a social-psychological concept. Self and Identity, 3(4), 339-354. doi:10.1080/13576500444000119 
Erber, M. W., \& Erber, R. (2001). The role of motivated social cognition in the regulation of affective states. In J. P. Forgas (Ed.), Handbook of affect and social cognition (pp. 275-290). Mahwah, NJ: Lawrence Erlbaum Associates.

Erber, R., Wegner, D. M., \& Therriault, N. (1996). On being cool and collected: mood regulation in anticipation of social interaction. Journal of personality and social psychology, 70(4), 757. doi:10.1037/0022-3514.70.4.757

Flett, G. (2018). The Psychology of Mattering. London: Academic Press.

Fromm, E. (1994). Escape from freedom. London: Macmillan.

Gabriel, S., Valenti, J., Naragon-Gainey, K., \& Young, A. F. (2017). The psychological importance of collective assembly: Development and validation of the Tendency for Effervescent Assembly Measure (TEAM). Psychological Assessment, 29(11), 1349-1362. doi:10.1037/pas0000434

Giddens, A., \& Pierson, C. (1998). Conversations with Anthony Giddens: Making sense of modernity. Stanford: Stanford University Press.

Goffman, E. (2009). Relations in public. New Brunswick NJ: Transaction Publishers.

Granovetter, M. S. (1973). The Strength of Weak Ties. American Journal of Sociology, 78(6), 13601380. doi:10.1086/225469

Greenfield, E. A., \& Marks, N. F. (2004). Formal volunteering as a protective factor for older adults' psychological well-being. The Journals of Gerontology Series B: Psychological Sciences and Social Sciences, 59(5), S258-S264. doi:10.1093/geronb/59.5.S258

Heidegger, M. (1978). On the essence of truth. In D. F. Krell (Ed.), Basic writings: Martin Heidegger. London: Routledge.

Honneth, A. (1995). The struggle for recognition: The moral grammar of social conflicts. Cambridge, UK: Polity Press.

Howarth, C. (2001). Towards a social psychology of community: A social representations perspective. Journal for the theory of social behaviour, 31(2), 223-238. doi:10.1111/14685914.00155

Huppert, F. A. (2009). Psychological Well-being: Evidence Regarding its Causes and Consequences. 
Applied Psychology-Health and Well Being, 1(2), 137-164. doi:10.1111/j.17580854.2009.01008.x

Ipsos. (2009). Social grade: A classification tool. Retrieved from https://www.ipsos.com/sites/default/files/publication/680003/MediaCT_thoughtpiece_Social_Grade_July09_V3_WEB.pdf

Jacobs, J. (1961). The death and life of great American cities. New York: Random House.

Jenkins, R., Meltzer, H., Jones, P., Brugha, T., Bebbington, P., Farrell, M., \& Crepaz-Keay, D. (2008). Foresight Mental Capital and Wellbeing Project. Mental health: Future challenges. Retrieved from http://eprints.lse.ac.uk/32763/

Jodelet, D. (1991). Madness and social representations. Hemel Hampstead: Harvester Wheatsheaf.

Joffe, H. (1996). The Shock of the New: A Psycho-dynamic Extension of Social Representational Theory. Journal for the Theory of Social Behaviour, 26, 197-219. doi: 10.1111/j.14685914.1996.tb00529.x

Joffe, H. (1999). Risk and 'the Other'. Cambridge: Cambridge University Press

Joffe, H. (2012). Thematic Analysis. In D. Harper \& A. R. Thompson (Eds.), Qualitative Research Methods in Mental Health and Psychotherapy: A Guide for Students and Practitioners (pp. 209-223). Oxford: Wiley Blackwell.

Joffe, H., \& Elsey, J. W. (2014). Free association in psychology and the grid elaboration method. Review of General Psychology, 18(3), 173. doi:10.1037/gpr0000014

Joffe, H., \& Smith, N. (2016). City dweller aspirations for cities of the future: How do environmental and personal wellbeing feature? Cities, 59, 102-112. doi:10.1016/j.cities.2016.06.006

Joffe, H., \& Yardley, L. (2004). Content and thematic analysis. In D. F. Marks \& L. Yardley (Eds.), Research methods for clinical and health psychology. London: Sage.

Jovchelovitch, S., \& Priego-Hernandez, J. (2013). Underground Sociabilities: Identity, culture and resistance in Rio de Janeiro's favelas. Brasilia UNESCO.

Kushlev, K., Heintzelman, S. J., Oishi, S., \& Diener, E. (2018). The declining marginal utility of social time for subjective well-being. Journal of Research in Personality, 74, 124-140. doi:10.1016/j.jrp.2018.04.004 
Lacan, J. (1997). The Seminar of Jacques Lacan: The Four Fundamental Concepts of Psychoanalysis. New York: WW Norton \& Company.

Landis, J. R., \& Koch, G. G. (1977). Measurement of observer agreement for categorical data. Biometrics, 33(1), 159-174. doi:10.2307/2529310

Levine, R. V., \& Norenzayan, A. (1999). The pace of life in 31 countries. Journal of cross-cultural psychology, 30(2), 178-205. doi:10.1177/0022022199030002003

Li, N. P., \& Kanazawa, S. (2016). Country roads, take me home... to my friends: How intelligence, population density, and friendship affect modern happiness. British Journal of Psychology, 107(4), 675-697. doi:10.1111/bjop.12181

Liu, L. (2006). Quality of Life as a Social Representation in China: A Qualitative Study. Social indicators research, 75(2), 217-240. doi:10.1007/s11205-004-3198-Z

Mikulincer, M., \& Shaver, P. R. (2007). Attachment in adulthood: Structure, dynamics, and change. Guildford, UK: Guilford Press.

Markova, I. (2003). Dialogicality and social representations: The dynamics of mind. Cambridge: Cambridge University Press.

Markova, I. (2015). On thematic concepts and methodological (epistemological) themata. Papers on Social Representations, 24(2), 4.1-4.31.

Markova, I. (2016). The dialogical mind: Common sense and ethics. Cambridge: Cambridge University Press.

Marshall, S. K. (2001). Do I matter? Construct validation of adolescents' perceived mattering to parents and friends. Journal of adolescence, 24(4), 473-490. doi:10.1006/jado.2001.0384

Milgram, S. (1970). The experience of living in cities. Science, 167(3924), 1461-1468. doi:10.1126/science.167.3924.1461

Morrow, V. (2001). Networks and neighbourhoods: children's and young people's perspectives. Retrieved from https://bit.ly/2lmJgnE

Moscovici, S. (1961/1976). La psychanalyse, son image et son public. Paris: Presses universitaires de France. 
Moscovici, S. (1984). The phenomenon of social representations. In R. Farr \& S. Moscovici (Eds.), Social representations (pp. 3-69). Cambridge: Cambridge University Press.

O'Connor, C., \& Joffe, H. (2020). Intercoder Reliability in Qualitative Research: Debates and Practical Guidelines. International Journal of Qualitative Methods. doi: 10.1177/1609406919899220

Oldenburg, R. (1999). The great good place: cafés, coffee shops, bookstores, bars, hair salons, and other hangouts at the heart of a community (3rd ed.). New York: Marlowe \& Company.

Oldenburg, R., \& Brissett, D. (1982). The third place. Qualitative Sociology, 5(4), 265-284. doi:10.1007/BF00986754

ONS. (2015). Personal Well-being in the UK, 2014/2015. Retrieved from https://www.ons.gov.uk/peoplepopulationandcommunity/wellbeing/bulletins/measuringnation alwellbeing/2015-09-23

Patton M. Q. (1999). Enhancing the quality and credibility of qualitative analysis. Health services research, 34(5 Pt 2), 1189-1208.

Pavot, W., Diener, E., \& Fujita, F. (1990). Extraversion and happiness. Personality and individual differences, 11(12), 1299-1306.

Pinquart, M., \& Sörensen, S. (2000). Influences of socioeconomic status, social network, and competence on subjective well-being in later life: a meta-analysis. Psychology and aging, 15(2), 187. doi:10.1037/0882-7974.15.2.187

Proshansky, H. M. (1978). The City and Self-Identity. Environment and behavior, 10(2), 147-169. doi: $10.1177 / 0013916578102002$

Raque-Bogdan, T. L., Ericson, S. K., Jackson, J., Martin, H. M., \& Bryan, N. A. (2011). Attachment and mental and physical health: Self-compassion and mattering as mediators. Journal of Counseling Psychology, 58(2), 272-278. doi:10.1037/a0023041

Rosenberg, M., \& McCullough, B. (1981). Mattering: Inferred significance and mental health among adolescents. Research in Community and Mental Health, 2, 163-182.

Sandstrom, G. M., \& Dunn, E. W. (2014). Social Interactions and Well-Being: The Surprising Power of Weak Ties. Pers Soc Psychol Bull, 40(7), 910-922. doi:10.1177/0146167214529799 
Sartre, J.-P. (2007). Existentialism is a Humanism. New Haven: Yale University Press.

Shaftoe, H. (2008). Convivial urban spaces: Creating effective public places. London: Earthscan.

Simmel, G. (1903). The metropolis and mental life. In K. H. Wolff (Ed.), The Sociology of Georg Simmel. Glencoe, Illinois: The Free Press.

Simmel, G. (2002). The Metropolis and Mental Life. In G. Bridge \& S. Watson (Eds.), The Blackwell City Reader. Oxford: Wiley-Blackwell.

Simmel, G., \& Hughes, E. (1949). The Sociology of Sociability. American Journal of Sociology, 55(3), 254-261.

Smith, N., O'Connor, C., \& Joffe, H. (2015). Social representations of threatening phenomena: the selfother thema and identity protection. Papers on Social Representations, 24(2).

Taylor, C. (1994). The politics of recognition. In A. Gutmann (Ed.), Multiculturalism (pp. 25-73). Princeton, NJ: Princeton University Press.

Thoits, P. A. (2011). Mechanisms linking social ties and support to physical and mental health. Journal of Health and Social Behavior, 52(2), 145-161. doi:10.1177/0022146510395592

Turkle, S. (2015). Reclaiming conversation: The power of talk in a digital age. New York: Penguin Press.

Ueno, K. (2005). The effects of friendship networks on adolescent depressive symptoms. Social Science Research, 34(3), 484-510. doi:10.1016/j.ssresearch.2004.03.002

Wajcman, J. (2015). Pressed for time: The acceleration of life in digital capitalism. Chicago: University of Chicago Press. 
Tables and figures

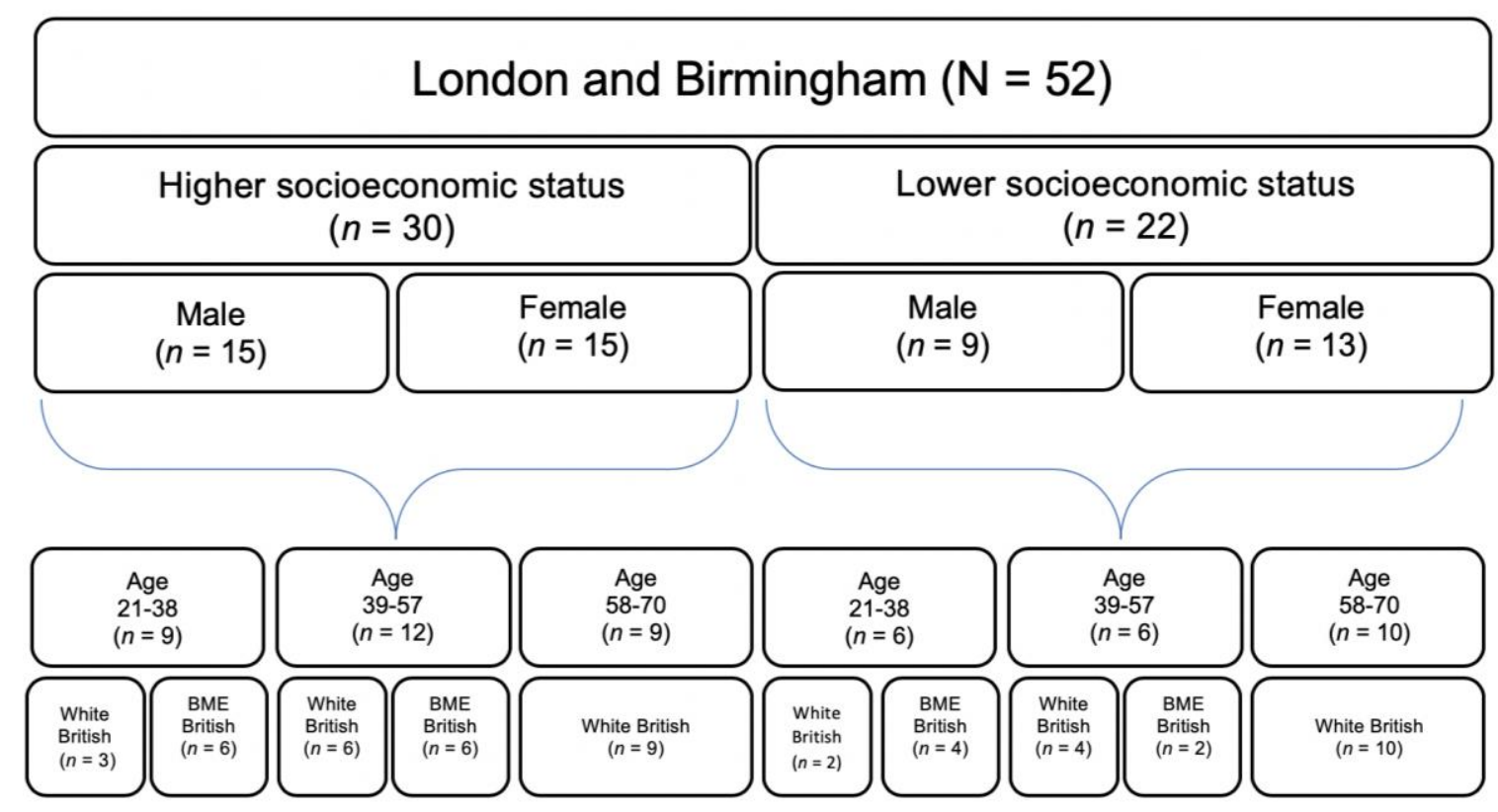

Figure 1. City-dweller demographics 
Instructions

I am interested in your interactions with acquaintances and strangers in the city. In the boxes below,

please write or draw the first four things that come to mind when you think of interacting with

acquaintances and strangers in the city. Please give only one thought/image per box.

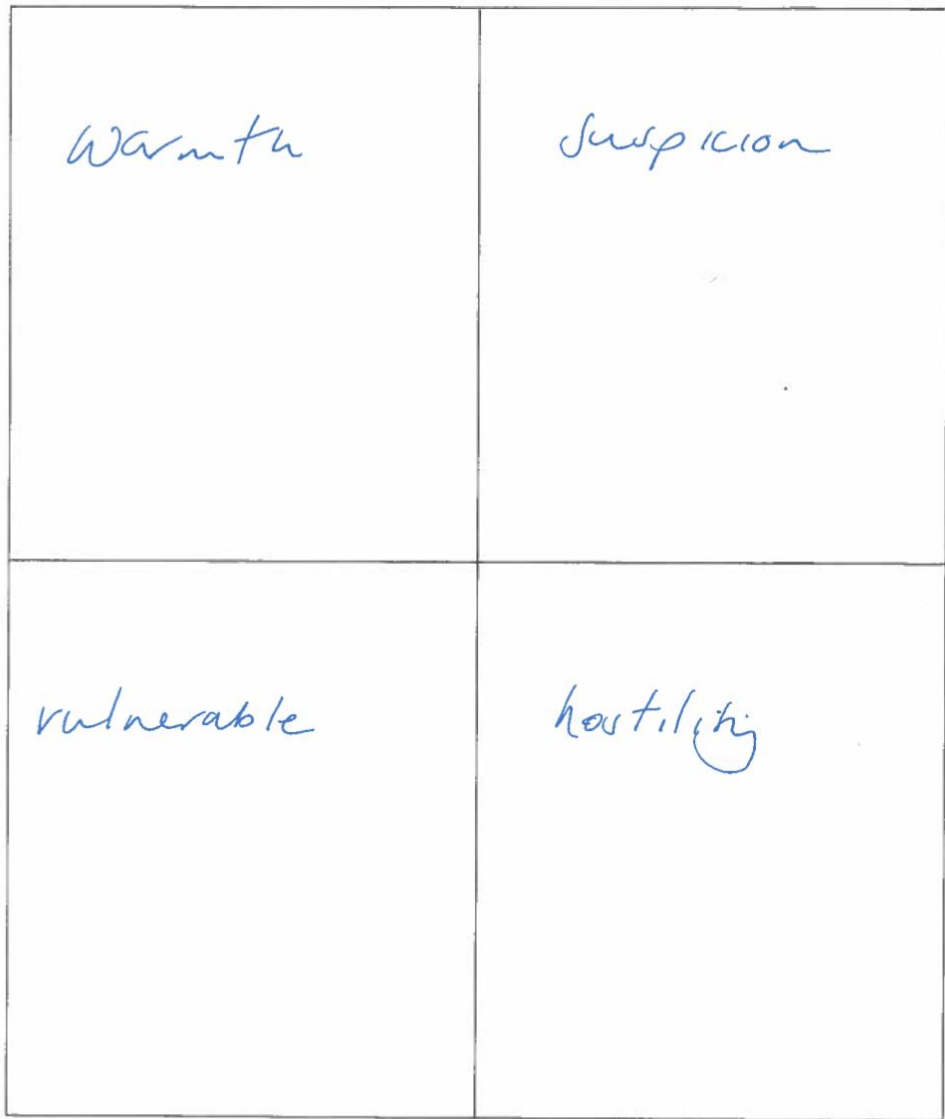

Figure 2. Example of weak ties grid 


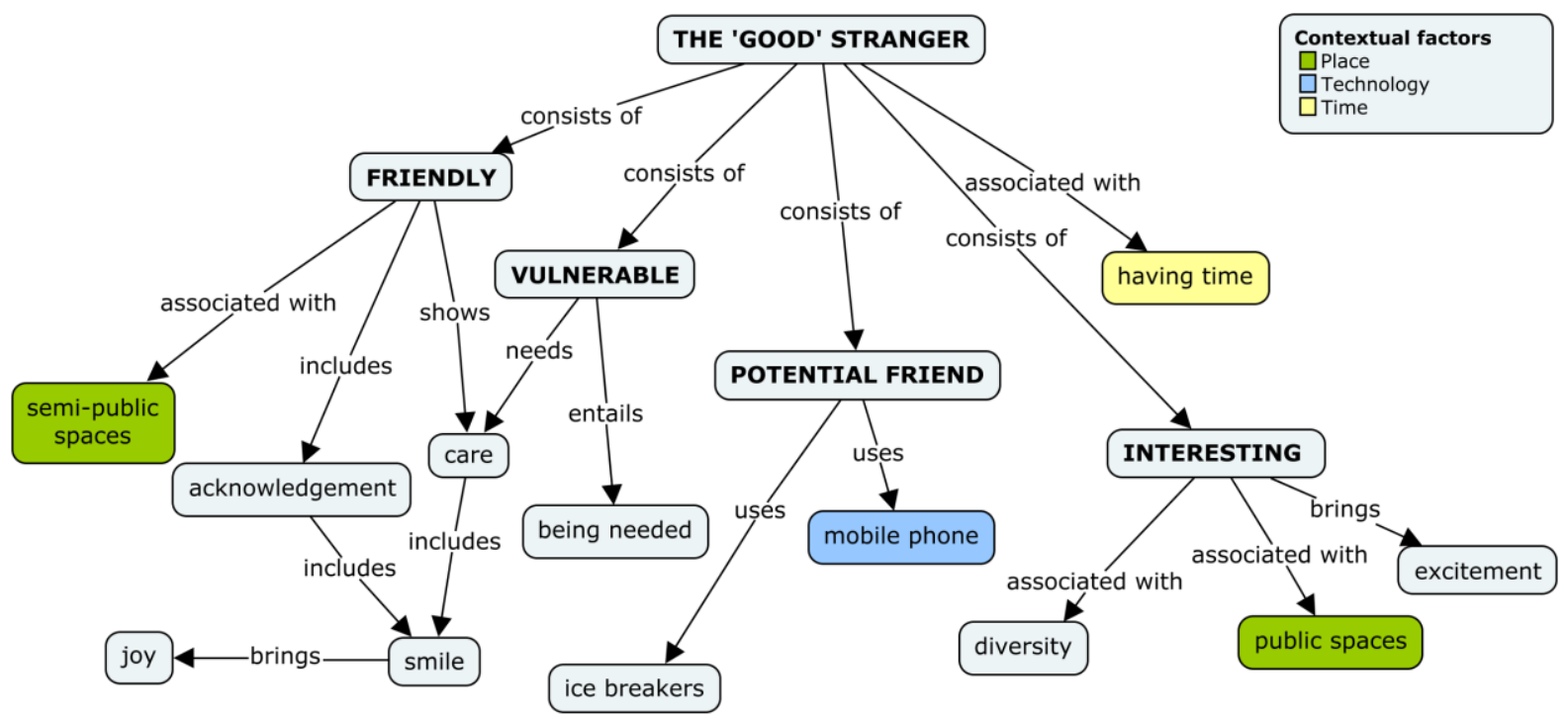

Figure 3. The 'good' stranger 


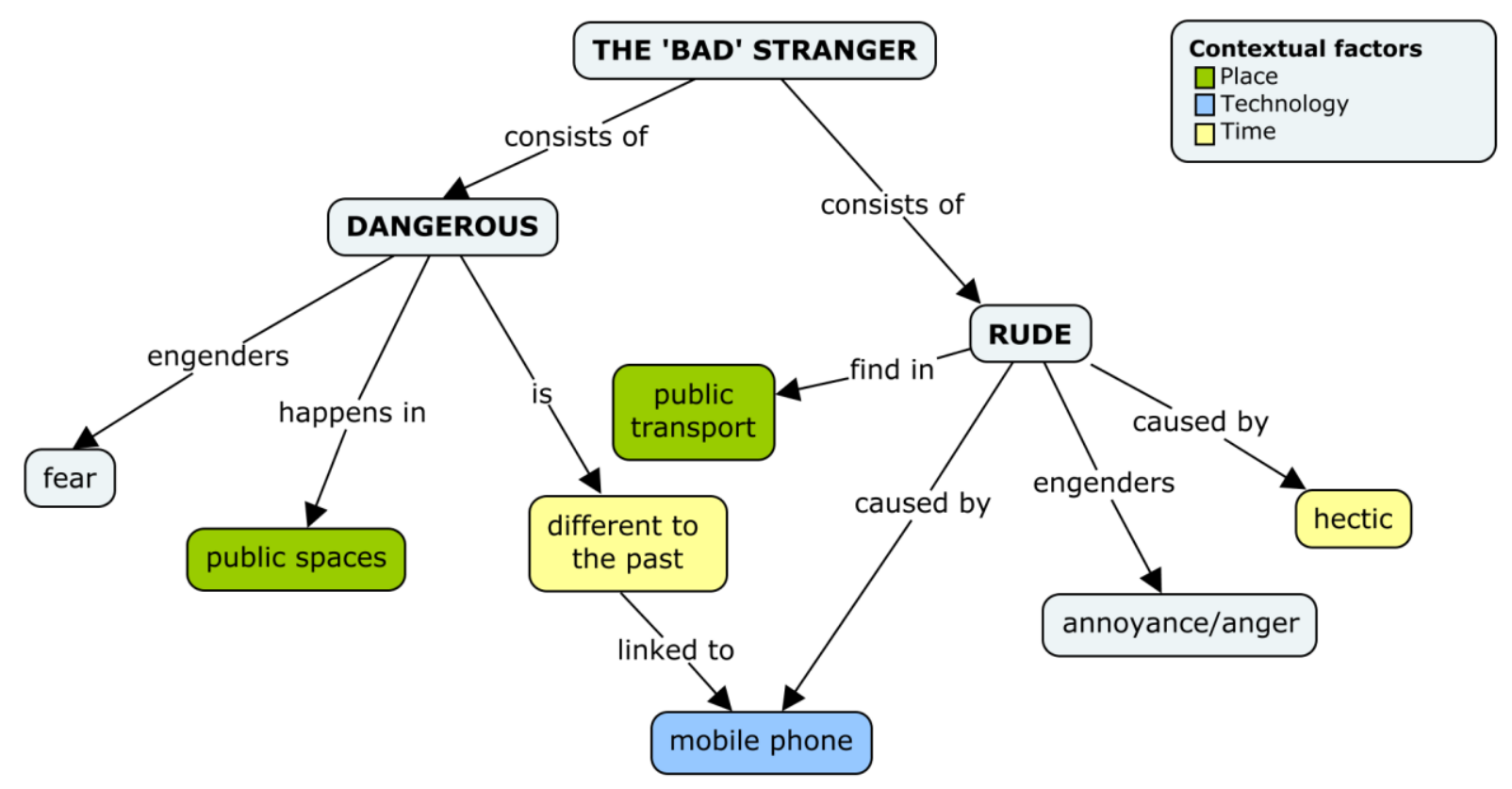

Figure 4. The 'bad' stranger 